\title{
Autism Spectrum Disorders: Assessment of Cognitive Abilities Using the non-verbal SON-R 6-40
}

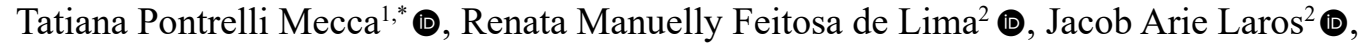 \\ Elizeu Coutinho de Macedo $^{3} \mathbb{\bullet}, \&$ Rosane Lowenthal ${ }^{1} \bullet$ \\ ${ }^{1}$ Faculdade de Ciências Médicas da Santa Casa de São Paulo, São Paulo, SP, Brasil \\ ${ }^{2}$ Universidade de Brasília, Brasília, DF, Brasil \\ ${ }^{3}$ Universidade Presbiteriana Mackenzie, São Paulo, SP, Brasil
}

\begin{abstract}
Cognition in individuals with Autism Spectrum Disorder (ASD) shows large variability. Nonverbal tests can be more suitable for cognitive assessment in this group. We investigated cognitive abilities in ASD using the SON-R 6-40 Nonverbal Intelligence Test. A total of 37 individuals with ASD (AG) aged 6-24 years participated. Cognitive assessment of the AG was done using the SON-R 6-40 and performance compared with the standardized sample which served as the control group (CG). Results showed lower subtest scores in the AG than in the CG. Approximately $84 \%$ of the AG had intellectual disability according to IQ scores. Individuals with preserved speech in the AG had higher IQ scores than patients without preserved speech. There was no relationship between intelligence and ASD symptom severity as reported by families.
\end{abstract}

KEYWORDS: Autistic Disorder; Intelligence; Psychological Assessment

\section{Transtorno do Espectro Autista:Avaliação de Habilidades Cognitivas Utilizando o Teste não-verbal SON-R 6-40}

\begin{abstract}
RESUMO - A cognição de indivíduos com Transtorno do Espectro Autista (TEA) apresenta grande variabilidade. Testes não-verbais podem ser mais adequados para avaliação cognitiva desta população. Investigou-se as habilidades cognitivas de indivíduos com TEA a partir do desempenho no Teste não verbal de inteligência SON-R 6-40. Participaram 37 indivíduos com TEA (GTEA) entre 6 e 24 anos, cujo desempenho no SON-R 6-40 foi comparado ao da amostra normativa do instrumento (GC). Houve pior desempenho do GTEA em todos os subtestes, com diferença significativa em relação ao GC. Quase $84 \%$ do GTEA apresentou QI compatível com deficiência intelectual. Aqueles com fala preservada apresentaram desempenho superior ao grupo não-verbal. Não houve relação entre inteligência e gravidade dos sintomas conforme relato das famílias.

PALAVRAS-CHAVE: autismo; inteligência; avaliação psicológica
\end{abstract}

The cognitive profiles of individuals with Autistic Spectrum Disorder (ASD) vary widely, with symptom severity differing among patients with the same diagnosis (Lai et al., 2013; Lord et al., 2014). This variability can also be seen in the same individual, with some abilities preserved and others more impaired, where the same individual serves as the reference parameter (Munson et al., 2008; Mecca et al., 2014). Thus, establishing cognitive profile by assessing different abilities in ASD allows interventions to be tailored that center on the patient's specific cognitive characteristics, whereby more preserved features can be exploited to train and strengthen impaired functions (Corbett, Carmean, \& Fein, 2009).

While useful for evaluating cognitive profile, assessing cognitive abilities in ASD is also essential in the diagnosis stage (Johnson \& Myers, 2007), given that around 45-60\% of cases are comorbid with intellectual disability (Baio et al., 2018; Carlsson et al., 2013; Joseph, 2011; Lai et al.,

\footnotetext{
*E-mail: tati.mecca@gmail.com

- Submetido: 21/07/2017; Revisado: 16/05/2018; Aceito: 20/10/2018.
} 
2013; Levy et al., 2009) and typically greater cognitive impairments in females (Banach et al., 2009; CDC, 2012). Identifying compromised abilities and their relationship with impairment severity can also further understanding on both the clinical presentation of the condition and its prognosis (Klin, 2009).

Development of cognitive abilities in ASD is associated with positive outcomes, as shown by many studies observing the relationship between cognition and adaptive functioning of these individuals. In general, findings indicate a significant, positive moderate relationship between intelligence and the abilities of communication, socialization and autonomy in activities of daily living (Kanne et al., 2011; Pugliesi et al., 2015). With regard to the presence and severity of symptoms, there is also evidence of a significant negative relationship between intelligence and the presence of behavioral deficits associated with the disorder, such as socialization, communication and restricted patterns of interest (Macedo et al., 2013; Mandelbaum et al., 2006; Mecca et al., 2014; Szatmari et al., 2003). Macedo et al. (2013) found that better performance on the non-verbal intelligence test SON-R 21/2-7[a] was inversely correlated with scores on the Autism Behavior Checklist (ABC). The $\mathrm{ABC}$ assesses the presence of atypical sensory responses, social attitude, use of body concept and objects, language and relating, which are areas of deficit in ASD. The authors found a strong significant negative correlation between intelligence and symptoms in ASD, particularly with the Execution index of the SON-R 21/2-7[a].

Measuring cognitive functioning based on performance on tasks that assess specific abilities has proven more meaningful than determining Intelligence Quotient (IQ) alone, which reflects total score on the intelligence test. This can be partially explained by the development and revision of theories and models underlying the construction of intelligence tests (Bergeron et al., 2006; Schneider \& McGrew, 2012). The Cattell-Horn-Carroll (CHC) psychometric model of cognitive abilities is based on 16 major domains, including fluid intelligence (Gf), comprehension/knowledge (Gc), visual processing (Gv), auditory processing (Ga), processing speed (Gps), shortterm memory $(\mathrm{Gsm})$ and long-term storage and retrieval (Glr). These broad domains are underpinned by 70 specific factors, assessed by the items of the tests (Schneider \& McGrew, 2012).

Bergeron et al. (2006) highlight that the different cognitive abilities have distinct degrees of importance for overall intellectual functioning. This depends on how much a given specific ability explains (correlates with) general intelligence. These aspects can be overlooked when only overall score (Total IQ) scores are analyzed. Consequently, there are advantages of using batteries that comprise a number of different tests, such as the SON-R (Laros et al., 2015; Tellegen \& Laros, 2014; 2017).
The use of batteries composed of different tests allows analysis of profiles which provide different types of information, such as elevation, dispersion and shape (Cronbach \& Gleser, 1953). Elevation is the mean obtained from all scores on the different subtests and represents global cognitive functioning reflected by Total QI. Dispersion (or scatter) refers to how much the scores of specific parts vary compared to the mean profile, including standard deviation, the range of scores on subtests and the degree of deviation of each score from the overall mean. Lastly, the shape indicates where high and low scores occur. This can be defined by an order of classification of the scores within the profile.

In the case of individuals with ASD, there is long-running discussion on the importance of using batteries incorporating different subtests to establish "strengths" and "weaknesses" with regard to cognitive abilities (Joseph, 2011; Klinger et al., 2009; Mandy, Murin, \& Skuse, 2015; Mayes \& Calhoun, 2008; Oliveras-Rentas et al., 2012). Concerning the type of instrument used for assessing individuals with ASD, the literature in the area is fairly unanimous on the advantages of non-verbal tests (Dawson et al., 2007; Grondhuis \& Mulick, 2013; Macedo et al., 2013; Mecca et al., 2014). The language deficits inherent to the disorder, such as echolalia (OliverasRentas et al., 2012), difficulty attributing mental states in certain verbal tasks, demands that depend on knowledge acquired from formal learning situations (vocabulary, for example) can limit the use of functional communication and fail to provide a reliable estimate of the reasoning and problem-solving capacity of individuals with ASD (Dawson et al., 2007; Grondhuis \& Mulick, 2013).

Beyond the dichotomy of the verbal versus non-verbal abilities extensively discussed in the literature (Mayes $\&$ Calhoun, 2008; Mecca et al., 2014), non-verbal tests containing items involving different demands can also be used for identifying profiles (Kuschner et al., 2007; Macedo et al., 2013; Mecca et al., 2014). Generally, studies using different instruments in individuals of different ages reveal better performance on visual processing and visuospatial tasks and greater difficulties on fluid reasoning tasks (Dias, 2013; Kuschner et al., 2007; Macedo et al., 2013; Mecca et al., 2014).

In Brazil, one of the few non-verbal tests for cognitive assessment is the SON-R version for children aged 2 years 6 months to 7 years and 11 years (Laros et al., 2015). This version comprises 4 tests and provides, besides general IQ (SON-QI), standardized scores on the Execution Scale (SON-ES) and Reasoning Scale (SON-RS). The Execution Scale assesses spatial abilities, visuo-motor and execution abilities, while the Reasoning Scale assesses abilities related with concrete and abstract reasoning. The first scale is composed of the Mosaic and Patterns subtests. The second scale consists of the Categories and Situations subtests. Studies using the SON-R 21/2-7 (Tellegen \& Laros, 2017; Tellegen et al., 1998) show that, compared to the SON-ES, 
the SON-RS domain is more strongly associated with verbal intelligence, language abilities and long-term memory.

Macedo et al. (2013) used the SON-R 21/2-7[a] to assess 18 children with ASD. Of the children assessed, 5 had a borderline Total IQ (70-79) and 3 had a Total IQ $<70$. Compared with the normative sample, the ASD group had significantly poorer performance on the Categories, Situations' and Patterns subtypes. The intra-group analysis revealed superior performance on Mosaics than for Categories and Patterns in the ASD group. Better performance was also observed on the Situations' subtest than the Categories subtest. Besides the performance profile on the instrument, negative correlations between IQ and increased ASD symptom severity were evident, corroborating earlier studies (Mecca et al., 2014; Szatmari et al., 2015)

Another version of the SON test, the SON-R 6-40 (Tellegen \& Laros, 2014), was standardized for use in Brazil and is currently undergoing assessment by the Evaluation System of Psychological Tests (SATEPSI) of the Federal Board of Psychology. This version is intended for use in individuals aged 6-40 years and the Brazilian standardized sample $(\mathrm{N}=1,360)$ contains individuals from 39 cities situated in Brazil's five geographic regions.

The SON-R 6-40 consists of four subtests: Analogies, Mosaics, Categories and Patterns. The SON-R 6-40 centers on measuring fluid intelligence, which can be defined as the ability to resolve problems about which the person holds little prior knowledge (Carroll, 2005). The tasks proposed in the subtests can be explained by a general dimension, according to studies of the internal structure of the test (Laros et al., 2015; Lima, 2018). However, some studies involving individuals with intellectual disability show two factors, the first comprising reasoning subtests and the second execution subtests (Alves \& Laros, 2017; Tellegen \& Laros, 2014).

In addition to the standardization study, validity studies of the SON-R 6-40 and other intelligence tests have been conducted in Brazil, including: the BPR-5 (Laros et al.,
2015); WISC-IV (Lima \& Laros, 2017); the Raven's Progressive Colored Matrices - Special Scale, the Columbia Mental Maturity Scale and the TONI-3 (Form A) Non-verbal Intelligence Test (Alves, 2016). Some characteristics of the SON-R 6-40 suggest it is a promising instrument for use in hard-to-test individuals. These characteristics include attractive materials, variety of tasks, opportunity to perform an active role, detailed examples, feedback from examiner, easy entry level and adjustment process which can reduce application time of the subtests and improve engagement of the respondent for task completion (Tellegen \& Laros, 2014). These authors found evidence supporting the validity of the SON-R 6-40 in a sample of individuals with severe learning and communication difficulties and in children with Attention Deficit Hyperactivity Disorder (ADHD).

Given the benefits of using non-verbal test batteries (e.g. the SON-R 6-40) for assessing individuals with ASD, the dearth of national studies investigating the profile of cognitive abilities in this group and their relationship with symptoms of the disorder, the present study investigated the performance pattern of individuals with ASD on different subtests of the instrument, comparing it to a group of typically-developing control individuals. The relationship between performance on the SON-R 6-40 and behavioral aspects associated with autism symptom severity (e.g. socialization deficits, presence of repetitive behaviors, disorders of speech and communication) was also investigated.

In view of the language variability seen in individuals with ASD, and the fact that language is a key predictor of different outcomes (Pickles, Andreson, \& Lord, 2014), the performance of individuals with ASD on the SON-R 6-40 with preserved, minimally-functional speech and non-verbal subjects was compared. This is the first national study using the SON-R 6-40 in a group of patients with ASD. Therefore, data on the accuracy of SON-R 6-40 scores for the clinical sample are also given.

\section{METHOD}

A cross-sectional, correlational study of a convenience sample was conducted.

\section{Participants}

The participants were recruited, according to availability, from a referral care center for individuals with ASD, the venue for data collection. The study included individuals of both genders aged 6-24 years $(M=12.3 ; S D=4.6)$ and diagnosed with ASD by an interdisciplinary team from the same institution where data collection took place based on DSM-5 criteria (American Psychiatric Association [APA], 2014). Individuals with other genetic conditions concomitant with ASD or who failed to answer the SON-R 6-40 due to physical or sensory limitation or behavioral changes precluding a standardized assessment, were excluded. All individuals whose guardian signed the Free and Informed Consent Form and voluntarily agreed to remain in the room with examiners belonging to a team specialized in neuropsychological assessment of individuals with ASD were included in the study.

A total of 42 participants were initially selected. However, 5 were subsequently excluded for not understanding the test situation or instructions. Thus, this gave a final sample in ASD group (AG) of 37 participants, comprising 30 with preserved speech and 7 non-verbal individuals (without 
use of reference language). Regarding gender, the sample consisted of 25 males and 12 females at a ratio of around 2:1.

The control group (CG) was formed by selecting 37 individuals from the databased used for the standardization study of the SON-R 6-40 test for Brazil. The controls were of both genders, aged 6-22 years $(\mathrm{M}=12,1 ; S D=4.4)$, all children and adolescents were drawn from public schools $(\mathrm{N}=31)$, and the group included 6 adults. The subjects selected for the $\mathrm{CG}$ were matched with the clinical group for gender, age and type of school (in the case of children and adolescents).

\section{Instruments}

The study was based on the SON-R 6-40 non-verbal intelligence test which measures two broad cognitive abilities defined by the $\mathrm{CHC}$ model, namely, visual processing $(G v)$ and fluid intelligence $(G f)$ (Tellegen \& Laros, 2014). The test is applied individually and made up of four subtests: Analogies (36 items), Mosaics (26 items), Categories (36 items), and Patterns (26 items). The test incorporates an adjustment process, avoiding the presentation of very easy or very difficult items for the specific level of each participant. The Brazilian standardization study showed that the reliability coefficient of the subtests ranged from 0.88 to 0.90 (Lima, 2018). Table 1 provides a detailed description of the subtests making up the SON-R 6-40 test.

The number of ASD symptoms was determined by the Autism Behavior Checklist (ABC), comprising 57 questions divided into 5 major domains: language, body, relating, sensory stimulation and social attitude. Responses are dichotomous (subject displays the behavior or otherwise), but each item has a specific value (scored 1-4) according to the relevance of the symptom in the ASD condition, i.e. items more characteristic of the disorder are scored with 4 , whereas less characteristic items score 1. Investigation of the psychometric properties of the instrument for Brazil determined, for a cut-off score of 47 , a sensitivity of $92.1 \%$ and specificity of 92.6\% (Marteleto \& Pedromônico, 2005).
Mean score of participants with ASD on the ABC was 60.00 points $(\mathrm{SD}=25.49)$.

\section{Procedures}

Assessments using the SON-R 6-40 were performed individually during sessions of around 40 minutes. The screening questionnaire was administered to the main carer of the patient (individual accompanying patient since birth and responsible for daily care), a process that took 15 minutes. The instruments were applied at the specialized care center attended weekly by the participants. The present study complied with the ethical regulations provided for in resolution 196/96 on human research and was approved by the local Research Ethics Committee.

\section{Data Analysis}

Raw scores were converted to standardized scores based on the normative values of the SON-R 6-40 for Brazil. Standardized scores were used as opposed to raw scores because the latter incorporated shared variance with the age variable, which would have led to overestimation of values. First, the internal consistency for the sample with ASD was calculated based on the Alpha coefficient. To this end, the scores on each item of the SON-R 6-40 were taken into account. Coefficients for subtests and total score on the test were obtained.

The proportion (percentage) of individuals in each IQ classification was recorded. Descriptive analyses (mean, standard deviation and range) of the performance of the AG and CG groups on the SON-R 6-40 were carried out, together with analysis of effect size of difference in means using Cohen's $d$. The effect size of differences in means was calculated using the formula for Cohen's $d$ [mean II - mean I / V (sdII2 + sdI2)/2] (Vacha-Haase \& Thompson, 2004). According to Cohen (1988), the effect size values should be interpreted as follows: $0.0<d \leq 0.20=$ very weak effect; $0.20<d \leq 0.50=$ weak effect; $0.50<d \leq 0.80=$ moderate effect; $d \geq 0.80=$ strong effect.

Table 1

Description of SON-R 6-40 subtests

\begin{tabular}{|c|c|c|}
\hline Subtests & Description & Cognitive ability assessed \\
\hline Analogies & $\begin{array}{l}\text { Multiple-choice subtest comprising } 36 \text { items divided into three parallel series (items } 1 \mathrm{a}-12 \mathrm{a} \text {, items } \\
1 \mathrm{~b}-12 \mathrm{~b} \text { and items } 1 \mathrm{c}-12 \mathrm{c} \text { ). This task entails discovering what change took place to the first of a } \\
\text { pair of figures and then applying the same change to a second pair of figures. }\end{array}$ & $G f$ \\
\hline Mosaics & $\begin{array}{l}\text { Execution subtest comprising } 26 \text { items divided into two parallel series (items 1a-13a and } 1 \mathrm{~b}-13 \mathrm{~b} \text { ). } \\
\text { Using red, white and red-white square pieces, the subject has to copy the figure presented in a } \\
\text { framework. }\end{array}$ & $G v$ \\
\hline Categories & $\begin{array}{l}\text { Multiple-choice subtest comprising } 36 \text { items divided into three parallel series (items } 1 \mathrm{a}-12 \mathrm{a} \text {, items } \\
1 \mathrm{~b}-12 \mathrm{~b} \text { and items } 1 \mathrm{c}-12 \mathrm{c}) \text {. On this task, participants have to find the concept underlying the first } \\
\text { pictures presented and pick two pictures that possess this same feature. }\end{array}$ & $G f$ \\
\hline Patterns & $\begin{array}{l}\text { Execution subtest comprising } 26 \text { items divided into two parallel series (1a-13a and } 1 \mathrm{~b}-13 \mathrm{~b}) \text {. } \\
\text { Participants have to look at a pattern of lines and draw in the missing part. }\end{array}$ & $G v$ \\
\hline
\end{tabular}


Analysis of Pearson's correlation was performed to ascertain the relationship between cognition measured by the SON-R and symptoms assessed by the ABC. Correlations of scores were analyzed by subtest and general domains of the SON-R 6-40, and for the subscales and total score on the ABC. Lastly, performance on the SON-R 6-40 by ASD patients with preserved speech and by individuals considered non-verbal (no use of reference language) was compared. This language classification was done by the speechlanguage therapy team from the specialized care center.

\section{RESULTS}

The results of the analyses of internal consistency revealed a satisfactory Alpha coefficient for the AG group on the subtests Analogies $(0.93 ; 36$ items), Categories, $(0.93 ; 36$ items), Mosaics $(0.94 ; 26$ items) and Patterns (0.94; 26 items). The overall Alpha coefficient for all 134 items was 0.97 .

Table 1 presents the descriptive statistics of mean, standard deviation and range of standardized scores for each subtest and total IQ of the SON-R 6-40 for the AG and $\mathrm{CG}$. The differences between the means and their respective effect sizes are shown in Table 2.

The results given in Table 2 show that AG participants had, on average, lower performance on subtests and Total IQ compared to CG subjects. This shows that, overall, the AG had poorer cognitive abilities than the CG. Performance on each subtest and for Total IQ were compared. Effect size estimated by Cohen's d showed a large effect on all comparisons between means of subtests and overall scale ( $d$ $\geq 0.80$ ). The differences between groups were statistically significant for all measures.

Table 2 reveals intellectual level variability in the AG. Of the 37 participants with ASD, most had Total IQ scores on the SON-R 6-40 that indicated intellectual disability, i.e. $<$ 70 points $(\mathrm{N}=31 ; 83.8 \%)$. Only 5 individuals had borderline IQ of 70-79 points, and one patient had a low average IQ of $80-89$ points $(2.7 \%)$. None of the AG patients had an IQ classified as average, high average or superior. For the CG, only one subject had an IQ score indicating intellectual disability $<70$ points $(2.7 \%), 4$ were borderline $(10.8 \%), 4$ low average $(10.8 \%), 18$ average $(48.6 \%), 7$ high average $(18.9 \%)$ and $3(8.1 \%)$ had superior IQ.
The difference between means for total score on the SON-R 6-40 in patients with and without verbal language was also examined. Descriptive statistics of the two groups showed higher average Total IQ in the group with language $(M=60.1, S D=11.7)$ than in the group with no language $(M=51.9, S D=12.1)$. This 8.2 point difference with confidence interval of [3.02 to 14.29] was not statistically significant $\left(t_{(35)}=1.66 p=0.81\right)$. However, the effect size of the difference between the groups was moderate $(\mathrm{d}=0.70)$, with higher overall performance (Total IQ) observed in the AG with preserved speech.

Comparison of performance of AG patients with and without preserved speech on the specific subtests revealed a statistically significant difference between groups on the Analogies subtest $\left(t_{(35)}=2.42, p=0.02\right)$, with a large effect size $(\mathrm{d}=1.43)$. The mean score was higher in the group with preserved language $(M=7.43 ; S D=3.04)$ compared to the group with no language $(M=4.57 ; S D=1.13)$. There was a tendency toward better performance by the preserved speech group on the Patterns subtest $\left(t_{(35)}=1.96, p=0.06\right)$, with a large effect size $(\mathrm{d}=0.83)$. Conversely, no statistically significant differences were found for the Categories $\left(t_{(35)}\right.$ $=0.94, \mathrm{p}=0.35)$ or Mosaics $\left(t_{(35)}=1.54 ; p=0.10\right)$ subtests. The difference in means of the groups on the Categories subtest had a small effect size $(\mathrm{d}=0.40)$, while the effect size for the Mosaics subtest was moderate $(\mathrm{d}=0.70)$.

Lastly, the results of the analyses of Pearson's correlation between performance on the SON-R 6-40 (including Total IQ and specific subtests) and scores on the different $A B C$ domains, together with total score, are summarized in Table 3.

Table 2

Descriptive statistics by subtest and Total IQ in the two groups

\begin{tabular}{|c|c|c|c|c|c|c|c|c|}
\hline \multirow{2}{*}{ Subtests } & \multicolumn{3}{|c|}{ AG $(n=37)$} & \multicolumn{3}{|c|}{ CG $(n=37)$} & \multirow{2}{*}{ Difference (p)* } & \multirow{2}{*}{ Cohen's d } \\
\hline & Mean & $\mathrm{SD}$ & Range & Mean & $\mathrm{SD}$ & Range & & \\
\hline Analogies & 2.5 & 1.6 & $1-6$ & 9.7 & 3.1 & $4-16$ & $-7.2(\mathrm{p}<0.001)$ & 2.9 \\
\hline Mosaics & 3.7 & 2.4 & $1-9$ & 9.7 & 3.1 & $3-16$ & $-6.0(p<0.001$ & 2.2 \\
\hline Categories & 2.7 & 1.7 & $1-7$ & 9.8 & 3.1 & $4-15$ & $-7.1(p<0.001)$ & 2.6 \\
\hline Patterns & 4.0 & 2.3 & $1-8$ & 10.4 & 2.8 & $5-16$ & $-6.4(p<0.001)$ & 2.5 \\
\hline SON-IQ & 58.6 & 12.1 & $36-81$ & 99.2 & 15.5 & $69-130$ & $-40.7(p<0.001)$ & 2.9 \\
\hline
\end{tabular}

Notes: $\mathrm{SD}=$ Standard deviation; $*$ difference between means. 
Correlations between SON-R 6-40 subtests and language index and ABC index

\begin{tabular}{|c|c|c|c|c|c|c|}
\hline \multirow[b]{2}{*}{ Subtests } & \multicolumn{6}{|c|}{ Specific domains of $\mathrm{ABC}$} \\
\hline & $\mathrm{ABC}$ & SS & $\mathrm{RE}$ & $\mathrm{BO}$ & LG & SA \\
\hline Analogies & 0.08 & 0.11 & -0.03 & 0.01 & 0.14 & 0.09 \\
\hline Mosaics & 0.02 & 0.18 & -0.06 & 0.01 & 0.08 & 0.06 \\
\hline Categories & 0.05 & 0.06 & -0.03 & -0.05 & 0.19 & 0.03 \\
\hline Patterns & 0.13 & 0.15 & 0.07 & 0.08 & 0.07 & 0.17 \\
\hline Total IQ & 0.09 & 0.09 & -0.02 & 0.05 & 0.14 & 0.14 \\
\hline
\end{tabular}

Notes: $\mathrm{SS}=$ sensory stimulus; $\mathrm{RE}=$ relating; $\mathrm{BO}=$ use of body and objects; $\mathrm{LG}=$ language; $\mathrm{SA}=$ social attitude.

The data presented in Table 3 demonstrate no correlations between the ABC domains that indicate ASD symptoms and cognitive abilities assessed by the SON-R 6-40 subtests. This confirms that the number of symptoms involving changes in sensory stimuli processing, difficulties in relating, inappropriate use of body and objects, language impairments and social attitude was not associated with cognitive development of the study participants.

\section{DISCUSSION}

The objective of the present study was to investigate the performance of individuals with ASD on the SON-R 6-40 non-verbal intelligence test. Tests with non-verbal instructions and answers have been considered more suitable for assessing cognition in patients with ASD (Macedo et al., 2013; Mecca et al., 2014), whose diagnostic criteria include impairments in language and communication (APA, 2014; Oliveras-Rentas et al., 2012).

The conducting of this study was prompted by the dearth of studies in Brazil on the use of cognitive tests, particularly non-verbal forms, in individuals with ASD exploring the different profiles and their relationship with language and primary characteristics of the condition, as previously reported in the literature (Macedo et al., 2013; Mecca et al., 2014).

Alpha coefficients were first investigated, given the absence of studies on the accuracy of the SON-R 6-40 in individuals with ASD. The results showed satisfactory coefficients indicating good accuracy (APA, AERA, NCME, 2014) in the clinical sample of the present study. Good internal consistency was found both for subtest scores and Total IQ scores of the SON-R 6-40. This precision of the measures allowed subsequent analyses.

With regard to the different cognitive profiles, the present study was based on the elevation profile (Cronbach \& Gleser, 1953) which considers the total scores on the instrument. Related literature indicates that $45-60 \%$ of ASD cases occur with an associated intellectual disability (Baio et al., 2018; Carlsson et al., 2013; Joseph, 2011; Lai et al., 2013; Levy et al., 2009). Of the 37 participants diagnosed with the disorder in the present study, over $80 \%$ were found to have IQ $<70$, i.e. indicating intellectual disability. Thus, most of the sample were classified as cognitively disabled, demonstrating a global cognitive abilities profile well below the average expected for the normal population of the same age.

Establishing the general cognitive level in ASD is paramount given this aspect is often associated with adaptive functioning difficulties (Kanne et al., 2011; Pugliesi et al., 2015). Intelligence is a major predictor of more favorable prognosis in ASD (Kanne et al., 2011; Klin, 2009; Pugliesi et al., 2015) and, therefore, its assessment during or after the diagnostic process is important (Volkmar et al., 2014). Tests such as the SON-R 6-40 provide this possibility.

The lack of individuals with average or above average expected intelligence in the present study may have been due to bias derived from the convenience-based sample. Milder cases may not be admitted to the care center where the participants were recruited. In addition, individuals with higher cognitive level may be more difficult to identify. This is because these individuals have better adaptive functioning (Macedo et al., 2013; Mecca et al., 2014), exhibiting fewer behavioral problems and better understanding of context, whereby the school or family do not recognize the need for treatment or more specific services.

One of the exclusion criteria was participants unable to undergo formal testing due to cognitive and behavioral problems. Individuals who could not understand the testing situation did not do the test and were thus not included in the sample. It is important to highlight that the results of the present study describe the cognitive aspects of a sample which does not portray the full heterogeneity of the disorder.

The different cognitive levels observed in the present sample corroborates findings reported in the literature (Joseph, 2011; Klinger et al., 2009; Mandy et al., 2015; Mayes \& Calhoun, 2008; Oliveras-Rentas et al., 2012). 
One participant had low average intelligence, five were classified as borderline, while the majority of participants were classified as having intellectually disability. By and large, the findings of the present study are similar to the results of Macedo et al. (2013) that used the SON-R 21/2-7[a] in a sample of children with ASD, most of whom had low average IQ or below.

We compared the performance on the SON-R 6-40 of the AG and $\mathrm{CG}$ and found that the AG group had poorer performance than the $\mathrm{CG}$ on all specific (subtests) and general (Total IQ) measures. These findings closely mirror those of an earlier study by Macedo et al. (2013) using the SON-R 2 $1 / 2-7[a]$, a version for children aged under 7 years (Laros et al., 2015). In the study, the authors also observed a significant difference between groups on the Categories and Patterns tasks. This result suggests the impairments in the abilities assessed by these subtests and seen in earlier stages of development persist into adult life in individuals with ASD, whose performance remains lower than the typically developed group.

Macedo et al. (2013) observed no statistically significant difference on the Mosaic subtest, akin to the present study. This might be explained by the fact that the visuospatial abilities and executive demands on the SON-R 21/2-7[a] are initially simple. The SON-R $6-40$ on the other hand, contains items of greater complexity, leading to significantly lower performance by the AG compared to the CG. Also, the sample in the study by Macedo et al. (2013) contained fewer individuals with greater cognitive impairment. Age differences in the samples may also be a factor explaining these disparities, given that changes in cognitive development occur with age in ASD (Szatmari et al., 2015).

Although a core feature of the SON-R 6-40 is its nonverbal comprehension and expression, the use of language-related processes to access answers to the items cannot be ruled out. The present study results cannot confirm this affirmation, but point to the need for future studies investigating whether the language aspects in ASD are predictors of cognitive performance in tests of reasoning and execution with non-verbal instructions and answers, such as those in the SON-R tests. This is due to the fact that one of the results of the present study shows significantly superior performance of the ASD patients with preserved language than non-verbal individuals. The relationships of tasks requiring execution and reasoning with aspects of language in ASD might be due to a general factor of intelligence with which different domains are associated. Future studies involving a larger number of participants and determining the factor structure of the SON-R 6-40 in a sample of ASD patients, along with the use of specific tests for assessing language, can help elucidate this issue.

Finally, the results failed to show a relationship between performance on the SON-R 6-40 and scores on the ABC assessing language impairments, sensory stimuli and reactions, changes in use of body and objects, relationships and personal aspects. Similarly to the study by Macedo et al. (2013), significant moderate negative correlations between cognition and number of symptoms were expected. Although there is no absolute consensus in the area, national and international studies show that greater cognitive ability in ASD is associated with fewer symptoms of the disorder reported by families (Macedo et al., 2013; Mandelbaum et al., 2006; Mecca et al., 2014; Szatmari et al., 2003, 2015).

The lack of a relationship between performance on the SON-R 6-40 and ABC scores for caregiver-reported symptoms might be due to the low variability in scores on the instruments. The mean, standard deviation and range of scores by the AG on the SON-R 6-40 showed little performance variation. The premise for determining a correlation between two variables is to investigate the extent one changes when the other also changes. If little difference exists between them, this premise cannot be observed.

This is the first national study using the SON-R 6-40 to assess a group of individuals with ASD. The results elucidated the performance of this patient group relative to the control group (taken from a standardization sample for the instrument) and the cognitive profile when performance on the different subtests was compared and its relationship with external variables such as language and ASD symptoms.

In addition to the primary objective, these findings also provide evidence of the validity and accuracy of the SON-R 6-40 for a sample of 37 individuals with ASD, supporting future application of the instrument in clinical practice with this patient group. We highlight the importance of studies of this nature, given that these cognitive tests are widely used in different settings (clinical and research) for assessing individuals with ASD. 


\section{REFERENCES}

Alves, T. A. (2016). Evidências de validade e propriedades psicométricas do SON-R 6-40. Master thesis, Universidade de Brasília, Brasília, Brasil.

Alves, T. A., \& Laros, J. A. (2017). Propriedades psicométricas do SON-R 6-40 em pessoas com deficiência intelectual. Psicologia: Teoria e Prática, 19(2), 127-138. http://dx.doi. org/10.5935/1980-6906/psicologia.v19n2p151-163

American Psychiatric Association. (2013). Diagnostic and Statistical Manual of Mental Disorders (5th ed.). Author.

Banach. R., Szatmari, P., Goldberg, J., Tuff, L. P., Zwaigenbaum, L., \& Mahoney, W. J. (2009). Brief Report: Relationship between nonverbal IQ and gender in Autism. Journal of Autism and Developmental Disorders, 39(1), 188-193. https://doi. org/10.1007/s10803-008-0612-4

Bergeron, R., \& Floyd, R. G. (2006). Broad cognitive abilities of children with mental retardation: An analysis of group and individual profiles. American Journal on Mental Retardation, 111(6), 417-432. https://doi.org/10.1352/08958017(2006)111[417:BCAOCW]2.0.CO;2

Carlsson, L. H., Norrelgen, F., Kjellmer, L., Westerlund, J., Gillberg, C., Fernell, E. (2013). Coexisting disorders and problems in preschool children with Autism Spectrum Disorders. The Scientific World Journal, 2013, 213979. https://doi. org $/ 10.1155 / 2013 / 213979$

Carroll, J. B. (2005). The three-stratum theory of cognitive abilities. In D. P. Flanagan \& P. L. Harrison (Eds.), Contemporary intellectual assessment ( $2^{\text {nd }}$ ed., pp. 69-76). The Guilford Press.

CDC. (2012). Centers for Disease Control and Prevention. Prevalence of autism spectrum disorders-Autism and Developmental Disabilities Monitoring Network, 14 sites, United States, 2008. MMWR Surveill Summ, 61, 1-19.

Cohen, J. (1988). Statistical power analysis for the behavioral sciences. Lawrence Erlbaum Associates.

Corbett, B. A., Carmean, V., \& Fein, D. (2009). Assessment of neurospychological functioning in autism spectrum disorders. In S. Goldstein., J. A. Naglieri, \& S. Ozonoff(Eds.), Assessment of Autism Spectrum Disorders (pp. 253-289). Guilford Press.

Cronbach, L. J., \& Gleser, G. C. (1953). Assessing similarity between profiles. Psychological Bulletin, 50, 456-473.

Dawson, M., Soulières, I., Gernsbacher, M. A., \& Mottron, L. (2007). The Level and Nature of Autistic Intelligence. Psychological Science, 18, 657-662. https://doi.org/10.1111/ j.1467-9280.2007.01954.x

Grondhuis, S. N., \& Mulick, J. A. (2013). Comparison of the Leiter International Performance Scale-Revised and the StanfordBinet Intelligence Scales, in children with autism spectrum disorders. American Journal on Intellectual and Developmental Disabilities, 118, 44-54. https://doi.org/10.1352/1944-7558118.1.44

Johnson, C. P., \& Myers, S. M. (2007). Identification and evaluation of children with autism spectrum disorders. Pediatrics, 120(5), 1183-1215. https://doi.org/10.1542/peds.2007-2361

Joseph, R. M. (2011). The significance of IQ and differential cognitive abilities for understanding ASD. In D. A. Fein (Ed.), The Neuropsychology of Autism (pp. 281-294). Oxford University Press.

Kanne, S. M., Gerber, A. J., Quirmbach, L. M., Sparrow, S. S., Cicchetti, D. V., \& Saulnier, C. A. (2011). The role of adaptive behavior in autism spectrum disorders: Implications for functional outcome. Journal of Autism and Developmental Disorders, 41(8), 1007-1018. https://doi.org/10.1007/s10803010-1126-4
Klin, A. (2009). Subtyping the Autism Spectrum Disorders: Theoretical, research and clinical considerations. In S. Goldstein., J. A. Naglieri, \& S. Ozonoff (Eds.), Assessment of Autism Spectrum Disorders (pp. 91-116). Guilford Press.

Klinger, L. G., O'Kelley, S. E., \& Mussey, J. L. (2009). Assessment of intellectual functioning in Autism Spectrum Disorders. In S. Goldstein, J. A. Naglieri, \& S. Ozonoff (Eds.), Assessment of Autism Spectrum Disorders (pp. 209-252). Guilford Press.

Kuschner, E. S., Bennetto, L., \& Yost, K. (2007). Patterns of nonverbal cognitive functioning in young children with Autism Spectrum Disorders. Journal of Autism and Developmental Disorders, 37, 795-807. https://doi.org/10.1007/s10803-0060209-8

Lai, M. C., Lombardo, M. V., Chakrabarti, B., \& Baron-Cohen, S. (2013). Subgrouping the Autism "Spectrum": Reflections on DSM-5. PLoS Biology, 11(4), e1001544. https://doi. org/10.1371/journal.pbio.1001544.

Laros, J. A., Tellegen, P. J., Jesus, G. R., de \& Karino, C. A. (2015). SON-R 21/2-7[a]. Manual - Teste não-verbal de inteligência. Hogrefe-CETEPP.

Laros, J. A., Almeida, G. O. N., Valentini, F., \& Lima, R. M. F. (2015). Dimensionalidade e evidências de validade convergente do SON-R 6-40. Temas em Psicologia, 23, 929945. https://doi.org/10.9788/TP2015.4-10

Levy, S. E., Mandell, D. S., \& Schultz, R. T. (2009). Autism. Lancet, 374, 1627-38. https://doi.org/10.1016/S0140-6736(09)613763.

Lima, R. M. F. (2018). Teste não verbal de inteligência SON-R 6-40: validação e normatização para o Brasil. Doctoral dissertation, Universidade de Brasília, Brasília.

Lima, R. M. F., \& Laros, J. A. (2017). Evidências de validade convergente e discriminante dos escores do SON-R 6-40. Psicologia: Teoria e Prática, 19, 107-120. http://dx.doi. org/10.5935/1980-6906/psicologia.v19n1p107-120

Lord, C., Corsello, C., \& Grzadzinski, R. (2014). Diagnostic instruments in autistic spectrum disorders. In F. R. Volkmar, R. Paul, S. J. Rogers, \& K. A. Pelphrey (Orgs), Handbook of Autism and Pervasive Developmental Disorders (Fourth Edition, pp. 609-660). John Wiley \& Sons.

Macedo, E. C., Mecca, T. P., Valentini, F., Laros, J. A., Lima, R. M. F., \& Schwartzman, J. S. (2013). Using the Nonverbal Test SON-R 21/2-7[a] to assess children with Autism Spectrum Disorders. Revista Educação Especial, 26, 603-618. https:// doi.org/10.5902/1984686X9779.

Mandelbaum, D. E., Stevens, M., Rosenberg, E., Wiznitzer, M., Steinschneider, M., Filipek, P., \& Rapin, I. (2006). Sensorimotor performance in school-age children with autism, developmental language disorder, or low IQ. Developmental Medicine and Child Neurology, 48, 33-39. https://doi. org/10.1017/S0012162206000089

Mandy, W., Murin, M., \& Skuse, D. (2015). The cognitive profile in autism spectrum disorders. In: M. Leboyer., \& P. Chaste (Eds), Autism Spectrum Disorders: Phenotypes, mechanisms, and treatments (pp. 34-45). Karger.

Marteleto, M. R., \& Pedromônico, M. R. (2005). Validity of Autism Behavior Checklist (ABC): Preliminary study. Revista Brasileira de Psiquiatria, 27, 295-301. https://doi.org/10.1590/ S1516-44462005000400008

Mayes, S. D., \& Calhoun, S. L. (2008). WISC-IV and WIAT-II profiles in children with high-functioning autism. Journal of Autism and Developmental Disorders, 38(3), 428-439. https:// doi.org/10.1007/s10803-007-0410-4. 
Mecca, T. P., Orsati, F. T., \& de Macedo, E. C. (2014). Non-Verbal cognitive profile of young children with Autism Spectrum Disorders. Psychology, 5(11), 1404-1417. https://doi. org/10.4236/psych.2014.511151

Munson, J., Dawson, G., Sterling, L., Beauchaine, T., Zhou, A., Koehler, E., Lord, C., Rogers, S., Sigman, M., Estes, A., \& Abbott, R. (2008). Evidence for latent classes of IQ in young children with autism spectrum disorder. American Journal on Mental Retardation, 113(6), 439-452. https://doi. org/10.1352/2008.113:439-452.

Oliveras-Rentas, R. E., Kenworthy, L., Roberson III, R. B., Martin, A., \& Wallace, G. L. (2012). WISC-IV profile in highfunctioning autism spectrum disorders: Impaired processing speed is associated with increased autism communication symptoms and decreased adaptive communication abilities. Journal of Autism and Developmental Disorders, 42(5), 655664. https://doi.org/10.1007/s10803-011-1289-7.

Pickles, A., Anderson, D. K., \& Lord, C. (2014). Heterogeneity and plasticity in the development of language: A 17-year follow-up of children referred early for possible autism. Journal of Child Psychology and Psychiatry, 55(12), 1354-1362. https://doi. org/10.1111/jepp.12269.

Pugliese, C. E., Anthony, L., Strang, J. F., Dudley, K., Wallace, G. L., \& Kenworthy, L. (2015). Increasing adaptive behavior skill deficits from childhood to adolescence in autism spectrum disorder: Role of executive function. Journal of Autism and Developmental Disorders, 45(6), 1579-1587. https://doi. org/10.1007/s10803-014-2309-1.
Schneider, W. J., \& McGrew, K. S. (2012). The Cattell-Horn-Carroll Model of intelligence. In D. P. Flanagan \& P. L. Harrison (Eds.), Contemporary intellectual assessment: Theories, tests and issues (3rd ed., pp. 553-581). The Guilford Press.

Szatmari, P., Georgiades, S., Duku., Bennett, T. A., Bryson., Fombonne, E., Mirenda, P., Roberts, W., Smith, I. M., Vaillancourt, T., Volden, J., Wadell, C., Zwageinbaum, L., Elsabbagh, M., Thompson, A., \& Pathways in Study Team. (2015). Developmental trajectories of symptom severity and adaptive functioning in an inception cohort of preschool children with Autism Spectrum Disorder. JAMA Psychiatry, 72(3), 276-283. https://doi.org/10.1001/ jamapsychiatry.2014.2463

Szatmari, P., Tuff, L., Finlayson, M. A., \& Bartolucci, G. (1990). Asperger's Syndrome and Autism: Neurocognitive aspects. Journal of the American Academy of Child and Adolescent Psychiatry, 29, 130-136. https://doi.org/10.1097/00004583199001000-00021

Tellegen, P. J., \& Laros, J. A. (2017). Snijders-Oomen Non-verbal intelligence test $S O N-R$ 2-8. Hogrefe.

Tellegen, P. J., \& Laros, J. A. (2014). SON-R 6-40. Snijders-Oomen Non-Verbal intelligence test. Research report, instructions \& norms. Hogrefe.

Tellegen, P. J., Winkel, M., Wijnberg-Williams, B. J., \& Laros, J. A. (1998). Snijders-Oomen Non-verbal intelligence test SON-R 21/2-7: Manual and research report. Swets Test Publishers.

Vacha-Haase, T., \& Thompson, B. (2004). How to estimate and interpret various effect sizes. Journal of Counseling Psychology, 51(4), 473-481. 